\title{
Política de dividendos e fluxos de caixa: um estudo à luz da Teoria da Sinalização
}

\section{Dividend policy and cash flows: a study in the light of the Theory of Signs}

\author{
Dante Baiardo Cavalcante Viana Júnior ${ }^{1}$ \\ Vera Maria Rodrigues Ponte ${ }^{2}$
}

\section{Resumo}

O estudo investiga, pela ótica da Teoria da Sinalização, a relação entre a distribuição de dividendos e os fluxos de caixa futuros de 47 companhias listadas na BM\&FBovespa entre 2007 e 2013, compreendo 329 observações. Trata-se de estudo de natureza exploratória e descritiva, no que diz respeito aos seus objetivos, e de abordagem quantitativa, na medida em que os dados coletados foram submetidos a testes estatísticos. A análise dos dados deu-se com o uso de um modelo de regressão múltipla, por meio de uma análise de dados em painel, adotando-se como variável dependente o ROA em $t$ (proxy do fluxo de caixa) e como variáveis independentes Div./Ação em $t-1$ (proxy da política de dividendos), além de outras variáveis de controle. $\mathrm{Na}$ análise de regressão, verificou-se que a variável Div./Ação não pode explicar o ROA de forma significativa, rejeitando-se a hipótese do estudo. A pesquisa contribui para ampliar o espectro da pesquisa acerca da política de dividendos, ajudando na compreensão de possíveis fatores explicativos para a postura das companhias brasileiras no que diz respeito ao assunto.

Palavras chave: Política de Dividendos. Fluxo de Caixa. Teoria da Sinalização.

\section{Abstract}

The present study investigates, from the perspective of the Theory of Signs, the relationship between the distribution of dividends and the future cash flows of 47 companies listed on the BM\&FBovespa between 2007 and 2013, containing 329 observations. This is a study of descriptive and exploratory nature, with respect to

\footnotetext{
1 Graduado em Ciências Contábeis pela Universidade Federal do Ceará. Atualmente é professor do CEBRAC: Centro Brasileiro de Cursos e do Centro de Ensino Grau Técnico. dantebcviana@ gmail.com

2 Doutorado em Controladoria e Contabilidade. Atualmente é Professora Adjunta II da Universidade Federal do Ceará (UFC). vponte@fortalnet.com.br
} 
their goals, and quantitative approach, to the extent that the data collected were subjected to statistical tests. Data analysis occurred using a multiple regression model, using a panel data analysis, adopting as the dependent variable ROA t (cash flow proxy) and as independent variables Div./Stock in $t-1$ (dividend policyproxy), and other control variables. In regression analysis, it was found that the variable Div./Stock cannot explain with significance the ROA, rejecting the hypothesis of the study. This research contributes to broaden the spectrum of research on the dividend policy, helping in the understanding of possible explanatory factors for the position of Brazilian companies with respect to the subject.

Keywords: Dividend Policy. Cash Flow. Signaling Theory.

\section{Introdução}

Entende-se como política de dividendos a decisão da administração com relação à parcela do lucro líquido a ser retida na empresa, em contrapartida à parcela a ser distribuída aos investidores de capital (FONTELES et al., 2012).

A propósito desse conceito, Ross (2010) aponta que o retorno para os investidores pode ocorrer por meio de dividendos propriamente ditos ou por meio de juros sobre o capital próprio. Dividendos são parcelas do resultado da companhia distribuídas com os acionistas, respeitando o mínimo obrigatório definido no seu estatuto social ou, quando este for omisso, o mínimo legalmente estabelecido. Juros sobre o capital próprio são remunerações pagas aos acionistas, cujo valor, além de poder ser deduzido da base de cálculo do Imposto de Renda, pode compor o valor do dividendo mínimo obrigatório.

Dada a relevância do assunto, algumas teorias foram desenvolvidas para explicar as políticas de dividendos adotadas pelas companhias. Dentre elas, destacam-se a Teoria da Irrelevância dos Dividendos (MILLER; MODIGLIANI, 1961), a Teoria do Pássaro na Mão (GORDON, 1963; LINTNER, 1956), a Teoria da Preferência Tributária (DAMODARAN, 2002) e a Teoria da Sinalização (SPENCE, 1973).

Mais recentemente, vários estudos examinaram a questão à luz da Teoria da Sinalização. Em sua obra clássica, Spence (1973) defendeu 
que, em mercados marcados por assimetrias de informação, os sinais são ações ou atributos dos indivíduos, os quais, por estruturação ou por acidente, acabam por alterar suas crenças, transmitindo informações a outros indivíduos no mercado.

É nesse sentido que estudos como os de Damodaran (2002), Fonteles et al. (2012), Naceur, Goaied e Belanes (2006) e Santos (2008) delineiam a política de dividendos, haja vista que, com base na Teoria da Sinalização, os valores de dividendos divulgados transmitem ao mercado mensagens, sinais que podem ser positivos ou negativos no que diz respeito ao julgamento dos investidores, já que, observando suas políticas de dividendos,os investidores em potencial podem diferenciar, entre duas empresas com lucros elevados, qual delas tem lucros mais sólidos ou anormais.

De acordo com a Teoria da Sinalização, o montante de dividendos divulgados por uma sociedade não é um mero acaso, sendo, tal informação, uma tentativa de transmitir sinais positivos para o mercado (FONTELES et al., 2012).

Nesse sentido, Weston e Copeland (1992) trazem em seus achados que o acréscimo nos dividendos indica que a firma gerará suficiente fluxo de caixa para suportar o alto nível dos valores declarados. No mesmo sentido, Jagannathan, Stephens e Weisback (2000) concluíram que as firmas maduras, com fluxos de caixa mais estáveis, é que elevam a distribuição de dividendos.

Alguns estudos identificam possíveis fatores explicativos das políticas de dividendos das empresas. Pesquisas empíricas, nacionais e estrangeiras, como as de Mota (2007), John e Kyazeva (2006) e Silva (2004) constatam que a variável fluxo de caixa apresenta relação positiva com a política de dividendos. Entretanto, identifica-se que os estudos que tratam do tema apresentam a limitação de considerar poucos exercícios anuais em seu universo amostral, utilizando uma média entre quatro e cinco anos. 
Diante do exposto, o estudo levanta a seguinte questão de pesquisa: as empresas que distribuem elevadas quantias de dividendos gerarão altos fluxos de caixa futuros?

Assim, o objetivo geral do estudo consiste em investigar, pela ótica da Teoria da Sinalização, a relação entre a distribuição de dividendos e os fluxos de caixa futuros. Assim, tem-se como objetivo específico analisar a evolução temporal dos montantes de dividendos distribuídos e dos fluxos de caixa gerados pelas companhias participantes da amostra.

Guardando consonância com os estudos de Weston e Copeland (1992) e Jagannathan, Stephens e Weisback (2000), que sugerem uma relação entre a distribuição de dividendos e os fluxos de caixa futuros, este estudo adota como hipótese que as empresas que divulgam a distribuição de elevados volumes de dividendos gerarão altos fluxos de caixa.

Dessa forma, ressalta-se a viabilidade e a oportunidade deste estudo, já que a distribuição de dividendos é um tema de abordagens controversas, pois não se sabe com precisão como as companhias e os investidores a interpretam (VERDI, 2001). Famá e Martins (2012) também comentam que no Brasil, em especial, existem particularidades que tornam o estudo do tema ainda mais interessante e polêmico. Ferreira Júnior (2010) argumenta, sobre a política de dividendos, ser um dos temas de maior discussão e críticas na área de finanças, tanto pela abrangência das áreas que envolve quanto pela falta de consenso que ainda persiste.

Este estudo foi estruturado em quatro seções, além desta introdução. Inicialmente, apresenta-se o referencial teórico. No tópico seguinte são abordados os procedimentos metodológicos. Na sequência, são demonstrados os resultados da pesquisa. Na quarta e última sessão, são explicitadas as conclusões do estudo. 


\section{Referencial teórico}

\subsection{Assimetria informacional e a sinalização}

O contexto geral da Teoria da Sinalização é discutido dentro das relações de mercado e na economia da informação, nas quais podem ocorrer situações de assimetria entre partes interessadas em formular negociações (BORGES; VIEIRA; SILVA, 2011). Nesse sentido, observase que as discussões sobre sinalização no meio acadêmico são precedidas pelo tema assimetria informacional, sendo este inicialmente abordado por Akerlof (1970), que mudou a concepção dos economistas sobre financiamento dos mercados (WU, 2004).

Em seu estudo clássico sobre o tema, Akerlof (1970) caracterizou bem a assimetria informacional com o conhecido Markets for lemons. 0 seu exemplo utiliza a situação de ofertas de carros usados no mercado norte-americano, considerando que entre as ofertas podem existir carros de boa qualidade e carros de má qualidade, ou de qualidade duvidosa, sendo estes últimos chamados pelo autor de "limões". Numa relação de compra e venda, o vendedor possui conhecimento adicional sobre o real estado dos carros quando comparado ao conhecimento dos compradores, condição essa que Ihe dá uma vantagem, enquanto ao comprador há o risco de escolher um carro ruim como se fosse um bom, caracterizando-se uma seleção adversa (BORGES; VIEIRA; SILVA, 2011).

Em consonância com o exposto anteriormente, Myers e Majluf (1984) estudaram a assimetria de informações existentes entre os investidores de capital (acionistas) e os gestores das companhias (administradores). Os autores discutem sobre a estrutura de capital das companhias e suas respectivas fontes de captação de recursos, sendo uma dessas fontes a emissão de ações. Nesse sentido, o referido estudo levanta a reflexão de que insiders (gestores) possuem um nível mais elevado de informações sobre a companhia, em contrapartida aos investidores, o que poderia causar uma subavaliação por parte do mercado. 
Por conseguinte, valendo-se de um maduro campo científico no que diz respeito à assimetria informacional, surge a Teoria da Sinalização, defendida no estudo clássico de Spence (1973). Segundo Spence (1973), os sinais de mercado podem ser definidos como as atividades ou atributos dos indivíduos em um mercado em que, por estruturação ou por acidente, alteram as crenças e transmitem informações a outros indivíduos no mercado.

Assim, pode-se entender que a Teoria da Sinalização tem por objetivo analisar, também, as situações em que as partes de um contrato estão interessadas em sinalizar algumas características antes que ele seja firmado ou assinado (WU, 2004).

Nessa discussão, observa-se que alguns pesquisadores passaram a estudar uma possível relação existente entre a Teoria da Sinalização e a política de dividendos.

\subsection{Política de dividendos}

Pode-se entender como dividendos a distribuição, em dinheiro, do lucro apurado (ROSS, 2010) e a forma mais comum de se remunerar os investidores de capital. Segundo ludícibuset al. (2010), os dividendos podem ser classificados em prioritários e não prioritários, mínimos, fixos e obrigatórios e cumulativos e não cumulativos.

De acordo com a Lei $n^{\circ} 6.404 / 1976$, o direito dos dividendos prioritários é usufruído pelos acionistas preferencialistas, em detrimento dos ordinaristas. Consoante expressa o seu artigo 202, na hipótese de o estatuto ser omisso e a assembleia geral deliberar por alterá-lo, para introduzir norma sobre a matéria, o dividendo obrigatório não poderá ser inferior a $25 \%$ do lucro líquido ajustado (BRASIL, 1976).

A distribuição de dividendos é apenas uma das formas de remuneração dos acionistas. O ICPC 07, que trata da distribuição de lucros in natura, regulamenta que uma entidade pode distribuir com seus acionistas ou sócios, ou com detentores de títulos especificados como patrimoniais (ações, cotas etc.), lucros na forma de ativos, que não são 
o próprio caixa, genericamente qualificados como dividendos in natura (CPC, 2009).

Outra possibilidade, também comum, de remuneração dos acionistas são os juros sobre o capital próprio: remunerações calculadas a partir das contas do Patrimônio Líquido e limitadas à Taxa de Juros de Longo Prazo (TJLP) do período, metodologia criada pela Lei $\mathrm{n}^{\circ}$ 9.249/1995, com o objetivo de evitar um possível aumento na carga tributária das empresas em decorrência da extinção da correção monetária das demonstrações financeiras à época. Os juros sobre o capital próprio apresentam uma vantagem tributária, pois fica permitido, com base no artigo $9^{\circ}$, que a pessoa jurídica deduza, para efeito da apuração do lucro real, os juros pagos aos sócios ou acionistas, a título de remuneração do capital próprio, calculados sobre as contas do Patrimônio Líquido e limitados à variação da TJLP (Lei nº 9249, 1995). Assaf Neto (2009) ensina que,para fins de cálculo, o montante pago fica limitado a $50 \%$ do lucro líquido antes do imposto de renda, excluindo-se o valor dos próprios juros sobre o capital próprio, ou a $50 \%$ dos lucros acumulados de exercícios anteriores, o que for maior.

Pode-se entender como política de dividendos de uma empresa qualquer o pagamento direto pela sociedade aos acionistas, seja por meio de dividendos propriamente ditos, seja mediante juros sobre o capital próprio (ROSS, 2010), sendo essa política baseada nas regras impostas pela legislação brasileira, como também nas melhores práticas contábeis sugeridas nos normativos contábeis recentemente convergidos com os normativos internacionais. Outro fator que também influencia as políticas de dividendos das companhias são as práticas das firmas de sucesso impondo ao mercado financeiro padrões de política de dividendos dificilmente imitados por concorrentes sem sucesso.

A discussão sobre política de dividendos tem início em 1956, com o estudo clássico de Lintner (1956), seguido, logo depois, pela obra de Miller e Modigliani (1961). Mota (2007) afirma que após esses estudos, infindáveis análises foram feitas quanto à política de dividendos em nível internacional, procurando avaliar a relevância da política de dividendos, 
tais como os estudos de Black e Scholes (1974), Grullon, Michaely e Swaminathan (2002), La Porta et al., 2000), Michaely e Thaler (1967) e Miller e Scholes (1982).

Com essa concepção, alguns estudiosos analisaram a política de dividendos à luz da Teoria da Sinalização, como Damodaran (2002), Fonteles et al. (2012), Naceur, Goaied e Belanes (2006) e Santos (2008).

Damodaran (2002) sugere que a distribuição de dividendos é estratégica por parte dos gestores, já que o volume de dividendos ofertados aos acionistas é uma informação carregada de mensagens, sinais, que podem transparecer boas ou más aos olhos dos investidores. O autor também argumenta que essa seria uma boa forma de pequenas empresas transmitirem sinais ao mercado, haja vista que elas possuem poucas maneiras de transmitir informações.

Naceur, Goaied e Belanes (2006) dissertaram que o valor distribuído em dividendos com os investidores possui um importante conteúdo informacional, já que potenciais investidores podem diferenciar, entre duas empresas com lucros elevados, qual delas tem lucros mais sólidos ou anormais, por meio da simples análise as políticas de dividendos de ambas.

De acordo com Santos (2008), diante de uma política de distribuição de dividendos elevados, tende-se a reagir positivamente, já que cresce a confiança na empresa, aos olhos dos investidores. Por outro lado, uma diminuição é recebida como uma má notícia acerca das perspectivas futuras.

Fonteles et al. (2012) analisaram as empresas integrantes do Índice Dividendos (IDIV) da BM\&FBovespa no ano 2010. Com metodologia empírica, os autores afirmam que concentração, rentabilidade, prosperidade e setor são fatores condicionantes de políticas de dividendos elevados, concluindo, com base na Teoria da Sinalização, que as empresas estudadas transmitem sinal positivo ao mercado por meio do planejamento e pagamento de dividendos elevados. 
Nessa direção, Miller e Modigliani (1961), em seu estudo, condicionado a mercados perfeitos, apontaram que uma das possíveis informações transmitidas ao mercado pela política de dividendos estaria relacionada com os fluxos de caixa.

Weston e Copeland (1992) trazem em seus achados que o acréscimo nos dividendos indica que a firma gerará suficiente fluxo de caixa para suportar o alto nível dos dividendos declarados.

Jagannathan, Stephens e Weisback (2000), ao analisarem empresas americanas na década de 1990, também indicaram em seus estudos, relacionando política de dividendos e recompra de ações, que os dividendos são pagos por empresas com maiores fluxos de caixa "permanentes", enquanto as recompras são utilizadas por empresas com fluxos de caixa mais altos e "temporários". As empresas que optam por recompra também apresentam fluxos de caixa e distribuições de dividendos mais inconstantes, concluindo que são as firmas maduras, com fluxos de caixa mais estáveis, que elevam a distribuição de dividendos.

Mota (2007) aponta, tomando por base os estudos de Aharony e Swary (1980), Grullon, Michaely e Swaminathan (2002) e Pettit (1972), que ocorre valorização das ações no mercado após elevações nos dividendos divulgados, assim como ocorre desvalorização após a divulgação de reduções.

Contestando tais argumentos, Mota (2007) disserta também que as elevações nos dividendos declarados pelas firmas são seguidas de quedas dos preços das ações, e as reduções nos dividendos são seguidas de elevações, citando, para ratificar tal argumento, os estudos de Benartzi, Michaely e Thaler (1997), DeAngelo e Skinner (1996).

Tais divergências de conclusões confirmam os argumentos de Verdi (2001), de que a distribuição de dividendos é um assunto polêmico, por ainda não se saber com precisão como as companhias e os investidores a interpretam. 


\section{Metodologia}

A pesquisa classifica-se como exploratória e descritiva, no que diz respeito aos seus objetivos. Considerando-se que o estudo investiga uma possível relação existente entre dividendos e fluxos de caixa futuros, utilizou-se a abordagem quantitativa, na medida em que os dados coletados foram submetidos a testes estatísticos (MARTINS; THEÓPHILO, 2009), procurando-se indicar a aceitação ou rejeição da hipótese da pesquisa.

Quanto à técnica empregada na coleta dos dados, a pesquisa classifica-se como bibliográfica e documental. Gil (2012, p. 45) argumenta que "a pesquisa documental vale-se de materiais que não receberam ainda um tratamento analítico, ou que ainda podem ser reelaborados de acordo com os objetos da pesquisa".

Para a formação da amostra, foram selecionadas as empresas listadas na BM\&FBovespa em 31/07/2014. Desse grupo, foram excluídas as companhias constituídas em 2014, aquelas que apresentaram resultado negativo em algum dos anos do período analisado (2007 a 2013) e as outliers, com o propósito de não enviesar os resultados (LIMA; MAROLDI; SILVA, 2013). Assim, a amostra do estudo reúne 47 companhias, compreendendo 329 observações.

Para a análise dos dados, fez-se uso de um modelo de regressão múltipla, por meio de uma análise de dados em painel, que mescla séries temporais e cortes transversais em um único estudo, isto é, a mesma unidade de corte transversal é acompanhada ao longo do tempo (GUJARATI; PORTER, 2011).

Com base nos estudos anteriores de Al Shabibi e Ramesh (2011), Adjaoud e Ben-Amar (2010), Mota (2007) e Santana (2005), adotouse como variável dependente o Retorno sobre o Ativo (ROA), utilizado como proxy do fluxo de caixa no tempo $t$. Como variável independente, utilizou-se a relação dividendo/ação, proxy da política de dividendos das companhias no tempo $t-1$, haja vista que se busca a relação dos dividendos com os fluxos de caixa futuros. 
Com o objetivo de se dar maior robustez ao modelo, foram incorporadas variáveis de controle identificadas a partir da literatura sobre a temática. No Quadro 1, apresentam-se as variáveis relacionadas e suas respectivas proxies. É possível observar que algumas delas foram escalonadas pelo ativo total, buscando-se um ajuste do efeito tamanho das empresas sobre o valor absoluto das variáveis (BUJAKI; RICHARDSON, 1997).

Quadro 1 - Variáveis independentes e respectivas proxies

\begin{tabular}{|c|c|c|c|}
\hline Variável & Proxy & $\begin{array}{l}\text { Impacto no } \\
\text { fluxo de caixa }\end{array}$ & Fundamentação \\
\hline $\begin{array}{l}\text { Tamanho da } \\
\text { empresa em } t\end{array}$ & $\begin{array}{l}\text { Logaritmo do ativo } \\
\text { total }\end{array}$ & - & $\begin{array}{l}\text { Máximo, Montezano e Brasil } \\
(2004) \\
\text { Kim, Mauer e Sherman } \\
(1998)\end{array}$ \\
\hline $\begin{array}{l}\text { Capital } \\
\text { circulante } \\
\text { líquido em } t\end{array}$ & $\begin{array}{l}\text { (Ativo circulante - } \\
\text { Passivo circulante) / } \\
\text { Ativo total }\end{array}$ & + & Assaf Neto e Silva (2012) \\
\hline Ebitda em $t$ & Ebitda / Ativo total & + & $\begin{array}{l}\text { Souza et al. (2008) } \\
\text { Assaf Neto (2009) } \\
\text { Moreira et al. (2013) }\end{array}$ \\
\hline $\begin{array}{l}\text { Lucro líquido } \\
\text { em } t-1\end{array}$ & $\begin{array}{l}\text { Lucro líquido/Ativo } \\
\text { total }\end{array}$ & + & $\begin{array}{l}\text { Finger (1994) } \\
\text { Lev, Sougiannis(2005) } \\
\text { Lustosa e Santos (2007) }\end{array}$ \\
\hline $\begin{array}{l}\text { Valor de } \\
\text { mercado em } t\end{array}$ & $\begin{array}{l}\text { Valor de mercado das } \\
\text { ações/Ativo total }\end{array}$ & + & $\begin{array}{l}\text { Máximo, Montezano e Brasil } \\
\text { (2004) }\end{array}$ \\
\hline
\end{tabular}

Fonte: Elaborado pelos autores.

Em consonância com os achados de Kim, Mauer e Sherman (1998) e Máximo, Montezano e Brasil (2004), espera-se que o tamanho da empresa tenha relação negativa com o volume de caixa, por se acreditar que as empresas maiores, ao ter melhor e maior acesso aos mercados de capitais, podem reter menos liquidez. Segundo os autores, o efeito se explica pelo ganho de escala em relação ao custo fixo originado quando da emissão de títulos.

Assaf Neto e Silva (2012) argumentam que quanto maior for o Capital Circulante Líquido (CCL) mantido por uma empresa, maior será 
sua folga financeira (maior geração de caixa) e menor será o seu risco de insolvência.

Assaf Neto (2009), Moreira et al. (2013) e Souza et al. (2008) encontraram relações empíricas entre o Ebitda e o fluxo de caixa das companhias abertas brasileiras. Os autores argumentam que o indicador tem uma forte relação com a geração de caixa, pois desconsidera as despesas e receitas operacionais que não afetam o caixa, considerando somente os resultados de natureza operacional que influenciam as disponibilidades.

Finger (1994), Lev e Sougiannis (2005), buscando variáveis explicativas para prever fluxos de caixa futuros, constatam empiricamente o poder preditivo do lucro líquido para prever tal indicador. A racionalidade que dá suporte a esse posicionamento deriva das estimativas utilizadas para mensurar o lucro pelo regime de competência (LUSTOSA; SANTOS, 2007).

No que diz respeito ao valor de mercado, espera-se uma relação positiva deste com a geração de caixa: crescimento de oportunidades futuras leva as empresas a reter mais liquidez, para fazer frente ao surgimento de oportunidades futuras (MÁXIMO; MONTEZANO; BRASIL, 2004).

Dessa forma, o modelo econométrico geral a ser utilizado no presente estudo, segundo Gujarati (2011), poderia ser assim expresso:

$$
R O A_{i, t}=\beta_{0}+\beta_{1 i, t-1} D I V+\beta_{2 i, t} T A M+\beta_{3 i, t} C C L+\beta_{4 i, t} E B T+\beta_{5 i,-1} L L+\beta_{6 i, t} V L M+\varepsilon_{i, t}
$$

Em que:

$R O A$ : fluxo de caixa

$D I V:$ dividendo/ação

TAM: tamanho

$C C L$ : capital circulante líquido

EBT: Ebitda

$L L$ : lucro líquido

VLM: valor de mercado

$\beta$ : coeficientes do modelo 
$\varepsilon$ : termo de erro

i: a empresa

$t$ : o tempo

Os dados para compor essas variáveis foram coletados da base de dados Economática ${ }^{\circledR}$.

Existem basicamente três formas de simplificar e ajustar o modelo geral a fim de torná-lo mais funcional: o Modelo Pooled, o Fixed-Effects Model (Modelo de Efeitos Fixos) e o Random Effects Model (Modelo de Efeitos Aleatórios).

A escolha do modelo mais adequado se dá mediante comparação por meio dos seguintes testes: (i) Teste $F$, que compara a regressão Pooled com o Modelo de Efeitos Fixos; (ii) Breusch-Pagan, que compara a regressão Pooled com o Modelo de Efeitos Aleatórios; e (iii) Teste de Hausman, que verifica qual modelo, Fixo ou Aleatório, é o mais adequado. Assim, após a realização dos testes, revelou-se mais apropriado o Modelo de Efeitos Aleatórios.

\section{Análise dos resultados}

Com o objetivo de apresentar uma visão geral do comportamento das variáveis utilizadas no modelo de regressão, elaborou-se a estatística descritiva das variáveis utilizadas no estudo entre 2007 e 2013, como mostra a Tabela 1.

Tabela 1 - Estatística descritiva das médias das variáveis do modelo (2007 a 2013)

\begin{tabular}{lccccccc}
\hline Variável & ROA & Div./Ação & $\begin{array}{c}\text { Ebitda/ } \\
\text { Ativo } \\
\text { Total }\end{array}$ & $\begin{array}{c}\text { Tamanho / CCL / } \\
\text { Ativo } \\
\text { Total }\end{array}$ & $\begin{array}{c}\text { LL I } \\
\text { Ativo } \\
\text { Total }\end{array}$ & $\begin{array}{c}\text { Valor de } \\
\text { Ativo } \\
\text { Total }\end{array}$ & $\begin{array}{c}\text { Mercado I } \\
\text { Ativo Total }\end{array}$ \\
\hline No de Observações & 329 & 329 & 329 & 329 & 329 & 329 & 329 \\
Média & 0,0833 & 0,8001 & 0,1510 & 6,4608 & 0,2605 & 0,0872 & 1,2135 \\
Mínimo & 0,0003 & 0,0105 & 0,0045 & 4,9125 & 0,0035 & 0,0003 & 0,0455 \\
Máximo & 0,4662 & 9,1208 & 0,5542 & 8,8768 & 0,7938 & 0,4662 & 8,2318 \\
Desvio-padrão & 0,0658 & 1,1208 & 0,0869 & 0,7187 & 0,1568 & 0,0662 & 1,2527 \\
Coeficiente de Variação & 0,7898 & 1,4009 & 0,5754 & 0,1112 & 0,6018 & 0,7589 & 1,0323 \\
\hline
\end{tabular}

Fonte: Elaborada pelos autores. 
Já durante a análise inicial dos dados, pôde-se observar que, dentre as variáveis estudadas, a Div./Ação é a que apresenta maior variabilidade dos dados ao longo dos anos analisados (2007 a 2013), com um coeficiente de variação correspondente a 140\%. Ainda nesse sentido, o Valor de Mercado é a segunda variável mais dispersa com coeficiente de variação equivalente a 103\%. Para as demais variáveis, observam-se coeficientes de variação semelhantes, indicando níveis semelhantes de variabilidade dos dados entre elas.

Buscando-se uma investigação mais precisa das principais variáveis investigadas (dividendos e fluxo de caixa), elaborou-se uma estatística descritiva ano a ano, conforme apresentado nas Tabelas 2 e 3.

Tabela 2 - Estatística descritiva: Div./Ação (2007 a 2012)

\begin{tabular}{lcccccc}
\hline Variável & $\mathbf{2 0 0 7}$ & $\mathbf{2 0 0 8}$ & $\mathbf{2 0 0 9}$ & $\mathbf{2 0 1 0}$ & $\mathbf{2 0 1 1}$ & $\mathbf{2 0 1 2}$ \\
\hline$N^{0}$ de Observações & 329 & 329 & 329 & 329 & 329 & 329 \\
Média & 0,6824 & 0,7170 & 0,7777 & 0,8313 & 0,9207 & 0,8711 \\
Mínimo & 0,0111 & 0,0157 & 0,0177 & 0,0104 & 0,0642 & 0,0715 \\
Máximo & 6,3878 & 4,2456 & 5,2602 & 5,6365 & 6,3748 & 9,1207 \\
Desvio-padrão & 1,1291 & 0,9443 & 1,0331 & 1,1660 & 1,0791 & 1,3684 \\
Coeficiente de Variação & 1,6545 & 1,3171 & 1,3284 & 1,4026 & 1,1719 & 1,5709 \\
\hline
\end{tabular}

Fonte: Elaborada pelos autores.

Observa-se que, ao longo dos anos analisados, os valores médios dos dividendos permanecem com valores semelhantes de coeficiente de variabilidade, com destaque para 2007 , com $165 \%$, indicando uma alta oscilação da variável Div./Ação ao longo do período. Observa-se, também, que as empresas distribuíram uma maior parcela de seus lucros em 2011, com uma média de $\mathrm{R} \$ 0,92$ por ação em circulação.

Tabela 3 - Estatística descritiva: ROA (2008 a 2013)

\begin{tabular}{lcccccc}
\hline Variável & $\mathbf{2 0 0 8}$ & $\mathbf{2 0 0 9}$ & $\mathbf{2 0 1 0}$ & $\mathbf{2 0 1 1}$ & $\mathbf{2 0 1 2}$ & $\mathbf{2 0 1 3}$ \\
\hline N $^{\circ}$ de Observações & 329 & 329 & 329 & 329 & 329 & 329 \\
Média & 0,1013 & 0,0814 & 0,0888 & 0,0790 & 0,0789 & 0,0703 \\
Mínimo & 0,0017 & 0,0025 & 0,0003 & 0,0151 & 0,0039 & 0,0006 \\
Máximo & 0,3457 & 0,3889 & 0,2438 & 0,3767 & 0,4661 & 0,2645 \\
Desvio-padrão & 0,0748 & 0,0670 & 0,0561 & 0,0610 & 0,0784 & 0,0524 \\
Coeficiente de Variação & 0,7387 & 0,8227 & 0,6328 & 0,7721 & 0,9934 & 0,7452 \\
\hline
\end{tabular}

Fonte: Elaborada pelos autores. 
$\mathrm{Na}$ Tabela 3, observa-se que os valores se mostraram mais homogêneos para a variável ROA, quando comparados à variável Div./ Ação. O maior coeficiente de variação para a variável em questão, no caso $99 \%$, registrou-se em 2012, seguido de $82 \%$ em 2009 e $74 \%$, em 2013. Conclui-se, portanto, que o comportamento da variável ROA foi bem disperso ao longo do período.

\subsection{Análise por segmento de listagem}

Investigou-se também o comportamento da variável Div./Ação por segmento de listagem, adotando-se a classificação da BM\&FBovespa, conforme se vê na Tabela 4.

Tabela 4 - Comportamento da variável Div./Ação por segmento de listagem

\begin{tabular}{lcccccccc}
\hline Setor & Quantidade & $\mathbf{2 0 0 7}$ & $\mathbf{2 0 0 8}$ & $\mathbf{2 0 0 9}$ & $\mathbf{2 0 1 0}$ & $\mathbf{2 0 1 1}$ & $\mathbf{2 0 1 2}$ & TOTAL \\
\hline Nível 1/ Nível 2 & 10 & 0,4962 & 0,5642 & 0,67705 & 0,64135 & 0,72785 & 0,6358 & 0,6230 \\
Novo Mercado & 21 & 0,6862 & 0,7220 & 0,7888 & 0,8408 & 0,9374 & 0,8856 & 0,8101 \\
Demais Empresas & 16 & 0,7241 & 0,7569 & 0,8179 & 0,8717 & 0,9620 & 0,9093 & 0,8403 \\
TOTAL & 47 & 0,5987 & 0,6518 & 0,7402 & 0,7488 & 0,8388 & 0,7666 & 0,7242 \\
\hline
\end{tabular}

Fonte: Elaborada pelos autores.

Observa-se que, em média, as companhias que não pertencem a nenhum dos níveis diferenciados de governança corporativa são aquelas que apresentam o maior volume de dividendos por ação, seguidas das companhias do Novo Mercado e daquelas pertencentes ao Nível 1 e ao Nível 2, apontando uma possível contradição com os resultados do estudo de Mota (2007), segundo o qual, ao contrário, as empresas mais preocupadas com a governança corporativa são aquelas que distribuem maior parcela de lucro aos acionistas.

Com o propósito de confirmar esses resultados, utilizou-se o teste estatístico de diferenças entre médias para duas amostras, o qual consiste em examinar se a diferença entre as médias de dois grupos de variáveis é significativamente relevante do ponto de vista estatístico. Assim, os dados dos três segmentos foram comparados entre si, a fim de se obter uma posição quanto à significância das diferenças observadas. 
Primeiramente foi testada a normalidade dos dados, por meio do teste de Kolmogorov-Smirnov, com o propósito de se optar por um teste paramétrico ou por um não paramétrico (MAROCO, 2003). Na sequência, realizou-se o teste de Levene, para se verificar se as variâncias eram homogêneas. Os resultados são apresentados na Tabela 5.

Tabela 5 - Resultados dos testes de normalidade e homogeneidade para a variável Div./Ação

\begin{tabular}{l|c|c|c}
\hline Segmento de listagem & $\begin{array}{c}\mathbf{N}^{\circ} \text { de } \\
\text { Observações }\end{array}$ & $\begin{array}{c}\text { Normalidade } \\
\text { Sig. }\end{array}$ & $\begin{array}{c}\text { Homogeneidade } \\
\text { Sig. }\end{array}$ \\
\hline Nível 1 e Nível 2 & 10 & 0,955 & 0,388 \\
Novo Mercado & 21 & 0,197 & 0,029 \\
\hline Nível 1 e Nível 2 & 10 & 0,955 & 0,078 \\
$\begin{array}{l}\text { Não Pertencentes a Segmentos } \\
\text { Diferenciados }\end{array}$ & 16 & 0,197 & 0,013 \\
\hline Novo Mercado & 21 & 0,078 & \\
$\begin{array}{l}\text { Não Pertencentes a Segmentos } \\
\text { Diferenciados }\end{array}$ & 16 & \\
\hline
\end{tabular}

Fonte: Elaborada pelos autores.

De acordo com os resultados obtidos, os dados relativos à variável Div./Ação das companhias pertencentes aos quatro grupos analisados apresentaram distribuição normal. Somente na comparação entre Nível 1 e Nível 2 / Novo Mercado se caracterizam como homogêneas.

Assim, dos dados obtidos no estudo, buscou-se tanto o sig. que supõe variâncias homogêneas, para comparar as médias entre Nível 1 / Nível 2 e Novo Mercado, quanto o sig. que supõe variâncias não homogêneas, para comparar as médias entre Nível 1 / Nível 2 e Não Pertencentes a Segmentos Diferenciados, bem como entre Novo Mercado e Não Pertencentes a Segmentos Diferenciados, como apresentado na Tabela 6. 
Tabela 6 - Resultados dos testes de diferenças entre médias

\begin{tabular}{l|c|c|c|c}
\hline Padrão contábil & $\begin{array}{c}\text { Médias Div.l } \\
\text { Ação }\end{array}$ & Homogeneidade & $\boldsymbol{T}$ & $\begin{array}{c}\text { Sig. } \\
\text { Bilateral }\end{array}$ \\
\hline Nível 1 e Nível 2 & 0,6330 & Homogêneo & $-1,169$ & $-1,427$ \\
Novo Mercado & 0,8101 & 0,252 \\
\hline Nível 1 e Nível 2 & 0,6330 & Não homogêneo & $-1,416$ & \\
$\begin{array}{l}\text { Não pertencentes a } \\
\text { segmentos diferenciados }\end{array}$ & 0,8403 & & $-1,768$ & 0,095 \\
\hline $\begin{array}{l}\text { Novo Mercado } \\
\text { Não pertencentes a } \\
\text { segmentos diferenciados }\end{array}$ & 0,8101 & Não homogêneo & $-1,156$ & 0,262 \\
\hline
\end{tabular}

Fonte: Elaborada pelos autores.

Os resultados indicam que, a um nível de 95\% de confiança, não há diferença significativa entre as médias dos três grupos.

\subsection{Modelo de efeitos aleatórios}

A Tabela 7 apresenta os coeficientes de correlação das variáveis do modelo.

Tabela 7 - Coeficientes de correlação das variáveis do modelo

\begin{tabular}{|c|c|c|c|c|c|c|c|}
\hline & ROA & DIV & EBITAD & ATIVO & $\mathrm{CCL}$ & LL & MERCADO \\
\hline ROA & 1,0000 & & & & & & \\
\hline DIV & 0,1213 & 1,0000 & & & & & \\
\hline$E B T$ & 0,8045 & 0,0420 & 1,0000 & & & & \\
\hline TAM & $-0,3055$ & $-0,1603$ & $-0,1811$ & 1,0000 & & & \\
\hline$C C L$ & 0,2752 & 0,0924 & 0,0979 & $-0,5562$ & 1,0000 & & \\
\hline$L L$ & 0,6551 & 0,1611 & 0,7310 & $-0,2924$ & 0,2750 & 1,0000 & \\
\hline VLM & 0,6581 & 0,0260 & 0,6367 & $-0,0996$ & 0,0225 & 0,6346 & 1,0000 \\
\hline
\end{tabular}

Fonte: Elabora pelos autores.

Com base na Tabela 7, observa-se que a maior correlação existente no modelo se verifica entre as variáveis Ebitda e ROA, de aproximadamente $80 \%$. Em contrapartida, a menor correlação das 
variáveis independentes com a dependente foi observada entre Div.l Ação e ROA, indicando baixa probabilidade de uma variável explicar a outra, e, consequentemente, uma possível rejeição da hipótese deste estudo, tomando-se por base os estudos de Weston e Copeland (1992) e Jagannathan, Stephens e Weisback (2000).

Como já mencionado na metodologia, utilizou-se uma regressão com dados em painel. Após os testes necessários, optou-se pelo Modelo de Efeitos Aleatórios. Adicionalmente, o método de correção de White (1980) foi aplicado à heterocedasticidade presente no modelo. A Tabela 8 apresenta os resultados da regressão.

Tabela 8 - Dados em painel: modelo de efeitos aleatórios

\begin{tabular}{|c|c|c|c|c|}
\hline & Coeficiente & Erro Padrão & $\mathrm{T}$ & P-Valor \\
\hline DIVit & 0,0013337 & 0,0050768 & 0,26 & 0,794 \\
\hline EBTit & 0,5798694 & 0,0882114 & 6,57 & 0,000 \\
\hline TAMit & $-0,0118366$ & 0,0237063 & $-0,50$ & 0,620 \\
\hline CCLit & 0,0472734 & 0,0307424 & 1,54 & 0,131 \\
\hline LLit & $-0,3927092$ & 0,0925839 & $-4,24$ & 0,000 \\
\hline VLMit & 0,0059869 & 0,0055544 & 1,08 & 0,287 \\
\hline _cons & 8,581465 & 16,40821 & 0,52 & 0,602 \\
\hline \multicolumn{2}{|c|}{$\mathbf{R}^{2}$ overall } & \multicolumn{3}{|c|}{0,6155} \\
\hline \multicolumn{2}{|c|}{$F(6,46)$} & \multicolumn{3}{|c|}{24,87} \\
\hline \multicolumn{2}{|c|}{ Prob. > F } & \multicolumn{3}{|c|}{0,000} \\
\hline
\end{tabular}

Fonte: Elaborada pelos autores.

Pelo teste de distribuição $\mathrm{F}$, seguindo-se a regra prática, observase um forte indício de que o modelo apresentado está bem ajustado, já que apresenta valor superior a 10. Para o teste $F$ de probabilidade, pode-se rejeitar a $1 \%$ de significância que todos os coeficientes são simultaneamente iguais a zero, ou seja, que pelo menos um parâmetro é diferente de zero.

O $\mathrm{R}^{2}$ overall indica como o modelo se ajusta em sua totalidade. Assim, constata-se que aproximadamente $61 \%$ da oscilação da variável dependente podem ser explicados pelas variáveis independentes 
embutidas no modelo, ou seja, que $61 \%$ da variação dos fluxos de caixa futuros podem ser explicados pelas variáveis Div./Ação, Ebitda, Tamanho, CCL, LL e Valor de Mercado.

Pelos coeficientes estimados no modelo, observa-se que a variável Ativo Total apresenta uma correlação inversa com o ROA, sugerindo que quanto maior for o Ativo Total de uma empresa, menor tende a ser sua folga financeira, confirmando conclusões de estudos nacionais e estrangeiros que tratam da temática (KIM; MAUER; SHERMAN, 1998; MÁXIMO; MONTEZANO; BRASIL, 2004). Entretanto, a correlação negativa estimada na regressão para a variável LL contradiz o estudo de Lustosa e Santos (2007), que analisaram 92 empresas listadas na BM\&FBovespa entre 1996 e 2004. Hipotetiza-se a divergência pelos diferentes métodos estatísticos utilizados neste estudo e no de Lustosa e Santos (2007). Para as demais variáveis, no que diz respeito ao impacto esperado, com base na fundamentação teórica, a relação pode ser justificada.

Ao se analisar o $p$-value, conclui-se que as variáveis Ebitda e LL podem explicar, a 1\% de significância, a variação do ROA. Entretanto, as variáveis Div./Ação, Ativo Total, CCL e Valor de Mercado não podem explicar a variação da variável dependente, rejeitando-se a hipótese deste estudo de que a política de dividendos, com base na Teoria da Sinalização, poderia sinalizar para o mercado uma geração de caixa futuro (JAGANNATHAN; STEPHENS; WEISBACK, 2000; WESTON; COPELAND, 1992).

\section{Considerações finais}

Este estudo investigou a relação entre a distribuição de dividendos e os fluxos de caixa futuros, tomando-se como base a Teoria da Sinalização. Adicionalmente, analisou a evolução temporal do valor dos dividendos distribuídos e dos fluxos de caixa gerados pelas companhias participantes da amostra, que reuniu 47 companhias listadas na BM\&FBovespa entre 2007 e 2013. 
Os achados revelaram que ao longo dos anos analisados os valores médios dos dividendos permaneceram com valores semelhantes de coeficiente de variabilidade, indicando um nível de dispersão semelhante. Observou-se, também, que as empresas distribuíram uma maior parcela de seus lucros em 2011, com uma média de R 0,92 por ação em circulação.

Conclui-se, também, que, em média, as companhias listadas nos segmentos diferenciados são as que apresentam o maior volume de dividendos por ação, seguidas das companhias do Novo Mercado e Nível 1/Nível 2, indicando uma possível contradição com os estudos de Mota (2007). Entretanto, essa rejeição não pode ser confirmada por meio do teste de diferenças entre médias, por não se mostrar significativa a um nível de $95 \%$ de confiança.

Por meio dos coeficientes de correlação, constatou-se que a maior correlação existente no modelo se dá entre as variáveis Ebitda e ROA, de aproximadamente $80 \%$, confirmando os estudos empíricos de Assaf Neto (2009), Moreira et al. (2013) e Souza et al. (2008).

$\mathrm{Na}$ análise de regressão, verificou-se que as variáveis Div./ Ação (t-1), Ativo Total, CCL e Valor de Mercado não podem explicar a oscilação da variável dependente (ROA, em $t$ ), rejeitando-se a hipótese do presente estudo de que a política de dividendos, com base na Teoria da Sinalização, poderia sinalizar para o mercado uma geração de caixa futuro (JAGANNATHAN; STEPHENS; WEISBACK, 2000; WESTON; COPELAND, 1992).

Por abordar uma temática ainda polêmica, já que os achados de diversos estudos sobre o assunto apresentam resultados contraditórios, os resultados contribuem para de alguma forma enriquecer a literatura de política de dividendos, ajudando na compreensão de possíveis fatores explicativos para a postura das companhias brasileiras no que diz respeito à distribuição de lucros com seus acionistas. Por outro lado, a utilização de informações referentes a apenas 58 companhias constitui uma das limitações do estudo. Espera-se, portanto, que futuros estudos envolvam maior número de observações, em período mais extenso, 
devendo incluir outras variáveis capazes de influenciar a política de dividendos, não abordadas na presente pesquisa.

\section{Referências}

ADJAOUD, F.; BEN-AMAR, W. Corporate governance and dividend policy: shareholders' protection or expropriation? Journal of Business Finance \& Accounting, Nova Jersey, v. 37, n. 5-6, p. 648-667, jun./jul. 2010.

AHARONY, Joseph; SWARY, Itzhak. Quarterly dividend and earnings announcments and stackholders. Returns: an empirical analysis. The Journal of Finance, New Jersey, v. 35, n. 1, p. 1-12, mar. 1980.

AL SHABIBI, B. K.; RAMESH, G. An empirical study on the determinants of dividend policy in the UK. International Research Journal of Finance and Economics, Seychelles, n. 80, p. 105-120, dez. 2011.

ARKELOF, A. The market for lemons: quality uncertainty and the market mechanism. The Quarterly Journal of Economics, United Kingdom, v.84, n. 3, p. 488-500, aug. 1970.

ASSAF NETO, A.. Finanças Corporativas e Valor. 4. ed. São Paulo: Atlas, 2009.

; SILVA, C. A. T.. Administração do capital de giro. 4. ed. São Paulo: Ed. Atlas, 2012.

BENARTZI, S.; MICHAELLY, R.; THALER, R. Do changes in dividends signal the future or the past. The Journal of Finance, New Jersey, v. 52, n. 3, p. 1.007-1.043, jul.1997.

BLACK, F.; SCHOLES, M.. The effects of dividend yield and dividend policy on common stock prices and returns. Journal of Financial Economics, Amsterdam, v. 1, n.1, p. 1-22, mayo 1974.

BORGES, E. F.; VIEIRA, E. T.; SILVA, C. A. T. Sinalização no contexto contábil: práticas de screening na contratação de serviços 
profissionais. Revista de Contabilidade do Mestrado em Ciências Contábeis da UERJ, Rio de Janeiro, v. 16, n. 1, art. 7, p. 97-114, jan./ abr. 2011.

BRASIL. Presidência da República. Lei n 6.404, de 15 de dezembro de 1976. Dispõe sobre as sociedades por ações. Diário Oficial [da] República Federativa do Brasil. Brasília, 1976. Disponível em: <http:// www.planalto.gov.br/ccivil_03/leis/L6404compilada.htm>. Acesso em: 10 jan. 2014.

. Presidência da República. Lei n 9.249, de 26 de dezembro de 1995. Altera a legislação do imposto de renda das pessoas jurídicas, bem como da contribuição social sobre o lucro líquido, e dá outras providências. Diário Oficial [da] República Federativa do Brasil. Brasília, 1995. Disponível em: <http://www.planalto.gov.br/ccivil_03/leis/ L9249.htm>. Acesso em: 10 jan. 2014.

BUJAKI, M. L.; RICHARDSON, A. J. A citation trail review of the uses of firm size in accounting research. Journal of Accounting Literature, Florida, v. 16, n. 1, p. 1-27, 1997.

COMITÉ DE PRONUNCIAMENTOS CONTÁBEIS (CPC). ICPC-07 - Distribuição de Lucros In Natura,Brasília, 2009. Disponível em: <http://www.cpc.org.br/CPC/Documentos-Emitidos/Interpretacoes/ Interpretacao?Id=16>. Acesso em: 10 jan. 2014.

DAMODARAN, A. Finanças corporativas aplicadas: manual do usuário. Tradução de Jorge Ritter. Porto Alegre: Bookman, 2002.

DEANGELO, H.; DEANGELO, L.; SKINNER, D.. Reversal of fortune, dividend singnaling and the disapperarance of sustained earnings growth. Journal of Financial Economics, Amsterdam, v. 40, n.3, p. 341-371, mar. 1996.

FAMÁ, R.; MARTINS, A. I.. O que revelam os estudos realizados no Brasil sobre política de dividendos? Revista administração de empresas, São Paulo, v. 52, n. 1,p.34-39, jan./fev. 2012. 
FERREIRA JÚNIOR, W. O. Evidências empíricas dos fatores determinantes das políticas de dividendos das firmas listadas na Bovespa. Facef Pesquisa - Desenvolvimento e Gestão, Franca, v. 13, n. 2, p. 190-203, maio, 2010.

FINGER, C. The ability of earnings to predict future earnings and cash flows. Journal of Accounting Research, Chicago, v. 32, n.2, p. 210223, Autumn 1994.

FONTELES, I. V. et al. Política de dividendos das empresas participantes do Índice de Dividendos da Bm\&F Bovespa. Revista Contabilidade Vista \& Revista, Universidade Federal de Minas Gerais, Belo Horizonte, v. 23, n. 3, p. $173-204$, jul./set. 2012.

GIL, Antônio Carlos. Como elaborar projetos de pesquisa. 4. ed. São Paulo: Atlas, 2012.

GORDON, M. J. Optimal investiment and financing policy. The Journal of finance. New Jersey, v. 18, n.2, p.264-72, maio 1963.

GRULLON, G.; MICHAELY, R.; SWAMINATHAN, B. Are dividend changes a sign of firm maturity? The Journal of Business, University of Chicago,Chicago, v. 75, n;3, p. 387-424, jul. 2002.

GUJARATI, D. N.; PORTER, D. C. Econometria básica. 5. ed. Rio de Janeiro: Amgh, 2011.

IUDÍCIBUS, S. et al. Manual de contabilidade societária: aplicável a todas as sociedades de acordo com as normas internacionais e do CPC. São Paulo: Atlas, 2010.

JAGANNATHAN, M.; STEPHENS, C. P.; WEISBACK, M. S. Financial flexibility and the coiche between dividends and stock repurchases. Journal of Financial Economics, Amsterdam, v. 57, n.3, p.355-384, set. 2000.

JOHN, K.; KNYAZEVA, A. Payout policy, agency conflicts, and corporate governance. New York: Working paper, 2006. 
KIM, Chang-Soo; MAUER, D. C.; SHERMAN, A. E. The determinants of corporate liquidy: theory and evidence. Journal of Financial and Quantitative Analysis. Seattle: University of Washington, v. 33, n.3, p. 335-359, Sep. 1998.

LA PORTA, R. et al. Agency Problems and Dividend Policies Around the World. The Journal of Finance, New Jersey, v. 55, n. 1, p. 1-33, feb. 2000.

LEV, B.; LI, S.; SOUGIANNIS, T. Accounting estimates: pervasive, yet of questionable usefulness. Working Paper, New York University, New York, n. 2451/27469, april, 2005.

LIMA, L. F. M.; MAROLDI, A. M.; SILVA, D. V. O. Outlier(s) nos cálculos bibliométricos: primeiras aproximações. Liinc em Revista, Rio de Janeiro, v. 9, n.1, p. 257-268, maio 2013.

LINTNER, J. Distribution of incomes of corporations among dividends, retained earnings and taxes. The American Economic Review, Harvard University, v. 46, n. 2, p. 97-113, May, 1956.

LUSTOSA, P. R. B.; SANTOS, A. Poder relativo do lucro contábil e do fluxo de caixas das operações para prever fluxos de caixa futuros: um estudo empírico no Brasil. Revista de Educação e Pesquisa em Contabilidade - REPeC, Brasília, v. 1, n. 1, art. 4, p. 39-58, jan/abr. 2007.

MARTINS, G. A.; THEÓPHILO, C. R. Metodologia da investigação científica para ciências sociais aplicadas. 2. ed. São Paulo: Atlas, 2009.

MAROCO, João. Análise estatística: com utilização do SPSS. Lisboa: Silabo, 2003.

MÁXIMO, I. R. de A.; MONTEZANO, R. M. S.; BRASIL, H. G. Liquidez: um estudo empírico de empresas brasileiras de capital aberto. In: ENCONTRO ANUAL DAASSOCIAÇÃO NACIONAL DOS PROGRAMAS DE PÓS-GRADUAÇÃO EM ADMINISTRAÇÃO-ENANPAD, 28., 2004, Curitiba. Anais... Curitiba: ANPAD, 2004. p. 1-14. 
MICHAELY, R.; THALER, R. H.; WOMACK, K. L. Price reactions to dividend initiations and omissions: overreaction or drift? The Journal of Finance, New Jersey, v. 50, n. 2, p. 573-608, Jun., 1967.

MILLER, M. H.; MODIGLIANI, F. Dividend policy, growth, and the valuation of shares. The Journal of Business, Chicago, v. 34, n. 4, p. 411-433, Oct. 1961.

; SCHOLES, M. Dividends and taxes: empirical evidence. Journal of Political Economy, Chicago, v. 90, n.6, p. 1118 - 1141, Dec. 1982.

MOREIRA, A. T. et al. Um estudo comparativo do Ebitda e do fluxo de caixa operacional em empresas brasileiras do setor de telecomunicações. Revista de Gestão, Finanças e Contabilidade, UNEB, Salvador, v. 4, n. 3, p. 05-22, set./dez., 2014.

MOTA, D. C. Dividendos, juros sobre capital próprio e recompra de ações: um estudo empírico sobre a política de distribuição no Brasil. 2007. 71 f. Dissertação (Mestrado em Administração de Empresas) Curso de Pós-Graduação da Escola de Administração de Empresas de São Paulo, Fundação Getúlio Vargas, São Paulo, 2007.

MYERS, S. C.; MAJLUF, N. S. Corporate financing and investment decisions when firms have information that invertors do not have. Journal of Financial Economics, Amsterdam, v. 13, n. 2, p. 187-221, jun. 1984.

NACEUR, S.; GOAIED, M.; BELANES, A. On the determinants and dynamics of dividend policy. International Review of Finance, Philadelphia, v. 6, n. 1-2, p. 1-23, Mar./Jun.2006.

PETTIT, R. Richardson. Dividend announcements, security performance, and capital market efficiency. The Journal of Financial, New Jersey, v. 27, n. 5, p. 993-1.007, Dec. 1972.

ROSS, S. A. Administração financeira. Tradução de Antônio Zoratto Sanvicente. 2. ed. São Paulo: Atlas, 2010. 
SANTANA, L. Relação entre dividend yield e retorno das ações abordando aspectos determinantes da política de dividendos: um estudo empírico em empresas com ações negociadas na Bovespa. 2005. 82f. Dissertação (Mestrado em Ciências Contábeis) - Fundação Instituto Capixaba de Pesquisas em Contabilidade, Economia e Finanças - FUCAPE, Vitória, 2005.

SANTOS, R. F. C. D. Perfil dos acionistas controladores das empresas brasileirase suas implicações para a política de dividendos. 2008. 118 f. Dissertação (Mestrado em Economia Aplicada) - Faculdade de Economia, Administração e Contabilidade de Ribeirão Preto, Universidade de São Paulo, Ribeirão Preto, 2008.

SOUZA, Marcos Antônio de et al. Evidenciação voluntária de informações contábeis por companhias abertas do sul brasileiro. Revista Universo Contábil, Blumenau, v. 4, n. 4, p. 39-56, out./dez. 2008.

SPENCE, M. Job market signaling. The Quarterly Journal of Economics, United Kingdom, v. 87, n.3, p. 355-374, Ago. 1973.

VERDI, R. S. A influência dos impostos sobre o pagamento de dividendos no preço das ações: um estudo do mercado brasileiro. 2001. 81 p. Dissertação (Mestrado em Administração) - Programa de Pós-Graduação em Administração, Universidade Federal do Rio Grande do Sul, Porto Alegre, 2001.

WESTON, J. F.; COPELAND, T. E. Managerial finance. 9. ed. [S.I.]: Dryden Press, 1992.

WHITE, H. A heteroskedasticity-consistent covariance matrix estimator and a direct test of heteroskedasticity. Econometrica, Nova Jersey, v. 48, n. 4, p. 817-838, Mayo1980.

WU, D. Y. T. Teoria da sinalização e educação. 2004. 60f. Monografia (Graduação em Economia) - Universidade Federal do Rio Grande do Sul, Porto Alegre, 2004.

Artigo recebido em: 21/03/2015

Aprovado em: 23/06/2015 